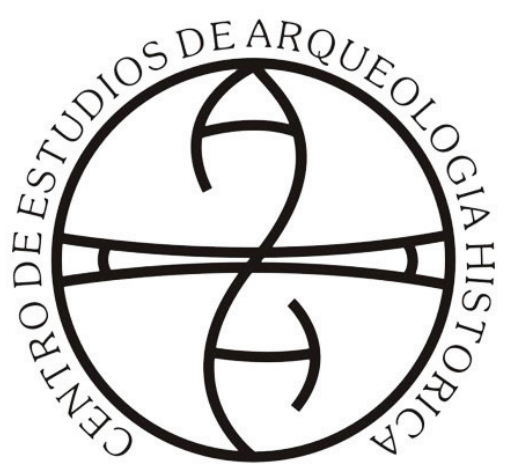

Centro de Estudios de Arqueología Histórica

Universidad Nacional de Rosario

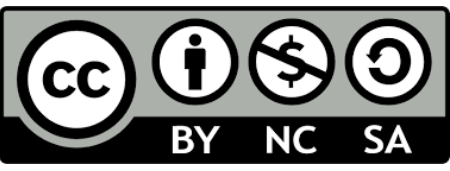

Teoría y Práctica de la Arqueología Histórica

Latinoamericana | Año IX, Volumen 11 | 2020

Revista del Centro de Estudios de Arqueología Histórica, Facultad de Humanidades y Artes,

Universidad Nacional de Rosario

https://teoriaypracticaah.unr.edu.ar/index.php/index

https://rephip.unr.edu.ar/handle/2133/14804

ISSN en línea: 2591-2801

ISSN versión impresa: 2250-866X

Atribución-NoComercial-CompartirIgual 4.0 Internacional (CC BY-NC-SA 4.0)

https://creativecommons.org/licenses/by-nc-sa/4.0/deed.es

María Virginia Elisa Ferro (ID.: https://orcid.org/0000-

0002-1719-2155). Hermenéutica en Arqueología Histórica

\title{
Hermenéutica en ArQueología Histórica
}

\section{Hermeneutics in Historical Archeology}

\author{
María Virginia Elisa Ferro *
}

\section{Resumen}

En el trabajo se presentan enfoques hermenéuticos contemporáneos: Hermenéutica simbólica, analógica, objetiva, entre otros. Dichos enfoques han sido aplicados en dominios disciplinares en Ciencias Sociales. En segundo lugar, se comenta el uso que ha tenido la Hermenéutica en Arqueología. Finalmente, se analizan implicancias posibles del empleo en la Arqueología Histórica, entendiéndose como el ámbito de las ciencias que aborda problemas del pasado humano ubicados en tiempos históricos y que puede utilizar para su resolución, información proveniente del registro arqueológico y de documentos escritos. Los datos que provienen, principalmente aunque no de manera excluyente, de la composición del registro arqueológico y de las fuentes históricas directas e indirectas, pueden resultar convergentes y orientarse a responder una misma pregunta. El foco de discusión en este trabajo se da principalmente a nivel metodológico.

Palabras clave: Hermenéutica simbólica, analógica, objetiva, Arqueología Histórica

\section{Abstract}

In the work we present different contemporary hermeneutic approaches: symbolic, analogical, objective hermeneutics, among others. Such approaches have been applied in a variety of disciplinary domains.

\footnotetext{
* Universidad Nacional de Río Cuarto. E mail: mveferro@gmail.com
} 
Secondly, the use of hermeneutics in Archaeology and History is analyzed.

Finally, possible implications of use in Historical Archaeology are analyzed, understood as the field of sciences that addresses problems of the human past located in historical times and that can be used for their resolution, information from the archaeological register and from written documents. The data that come, mainly but not exclusively, from the composition of the archaeological record and from direct and indirect historical sources, can be convergent and oriented to answer the same question. The focus of discussion in this work is mainly on the methodological level.

Key Words: Symbolic, analogical, objective hermenutics, Historical Archaeology

\section{Introducción}

En el trabajo se analizan enfoques hermenéuticos contemporáneos: Hermenéutica simbólica, analógica y objetiva. En tal sentido se explicitan orígenes, desarrollo, conceptos centrales, focalizándose aspectos metodológicos. En segundo lugar se hace referencia a tradiciones metodológicas en Ciencias Sociales, tales como Hermenéutica, Teoría Fundamentada, Fenomenología, Teoría de la Acción Participativa, Cartografía Social y Narrativas. En tercer lugar, se introduce la diferenciación de niveles de problemas en los que se ha estudiado el vínculo entre Arqueología e interpretación. Finalmente, nos preguntamos ¿Hasta qué punto se puede introducir un análisis en Arqueología Histórica que se conciba a nivel teórico como Hermenéutica Simbólica, Analógica u Objetiva?; y en segundo lugar: ¿qué uso de tradiciones metodológicas se ha hecho dentro del área?

\section{Enfoques hermenéuticos contemporáneos: hermenéutica simbólica, analógica, objetiva}

\section{Hermenéutica Simbólica}

Pensar en Hermenéutica Simbólica, es necesariamente retrotraerse al Círculo Eranos como punto fundacional en Suiza y a un proyecto interdisciplinario desde sus comienzos.

La perspectiva teórica de la hermenéutica simbólica, preocupada en mediar y profundizar en la complejidad de lo simplemente dado como dato objetivo de la época, procede del entrecruzamiento crítica contemporáneo de las diferentes ciencias humanas en torno al lenguaje y su sentido. Psicoanálisis, historia de las religiones, antropología, filosofía de las formas simbólicas, historia del arte, etc., todas estas disciplinas confluyen en un campo interdisciplinar a partir del cual se intenta comprender el mundo del hombre a través de sus configuraciones simbólicas (Solares, 2001: 8)

La Escuela de Eranos se halla representada por C.G. Jung; K. Kérenyi; M. Eliade A. Portmann, E. Neumann; H. Corbin; J. Campbell, entre otros, interesados en mediar entre el mythos y el logos, la concordancia entre contrarios (el imaginario simbólico, mátrix del pensamiento), la necesidad de lo diverso. No tiene intención de buscar explicaciones universales, más bien el hacer consciente al investigador de que sólo podemos juzgar a partir de nuestras propias categorías culturales, dónde el único modo de entender lo extraño no responde al régimen diurno de la imagen de la razón. A nivel metodológico, la hermenéutica se presenta como destino humano o como comprensión del mundo a través de expresiones 
culturales, simbólicas y lingüísticas, alrededor de las cuales toda cultura se organiza (Zabala, 2007).

Jung creyó en la universalidad de los símbolos arquetípicos, con la intención de contrastar el concepto de los signos (imágenes con connotación) con su significado y del "ajuste a la imagen", explorado con la asociación. Propuso dos enfoques para el análisis: el objetivo y el subjetivo. En el primero, cada persona en el sueño se refiere a la persona en sí; en el segundo cada persona representa un aspecto del soñador. No debía atribuirse significado a los símbolos oníricos sin una comprensión de la situación personal, por tanto describe dos enfoques para símbolos de los sueños: el causal y el final. En el enfoque causal, el símbolo se reduce a tendencias fundamentales; y en el final cabe la pregunta ¿Por qué este símbolo y no otro? (Osés, 1983).

Un aspecto clave es la comprensión de la relación entre individuo y psique; y la afirmación de que el inconsciente se expresa a través de arquetipos, que son proyecciones innatas entre las culturas y universalmente reconocidas y comprendidas. Es una manera de organizar cómo los seres humanos experimentan, lo que se evidencia a través de los símbolos que se encuentran en los sueños, la religión, el arte. Etc.

Jung identificó cinco arquetipos fundamentales: el materno; maná o poder espiritual; la sombra (incluye el sexo y los instintos); la persona (la imagen pública); y Anima y Animus (cualidades femeninas y masculinas). También distinguió funciones tales como: - sensaciones (supone la acción de obtener información a través de los significados de los sentidos); - el pensamiento (significa evaluar la información o las ideas de forma racional y lógica); - la intuición (considerado como un modelo de percepción que funciona fuera de los procesos conscientes); - el sentimiento (considerado como una respuesta emocional en general). Lo que constituyo la terapia desarrollada por Jung, se caracteriza por la conversación, e incluyó: el análisis de los sueños, la prueba de asociaciones de palabras o prueba de asociaciones libres y las actividades creativas (tales como pintura, teatro, danza, entre otros, como métodos de auto-expresión). (Jung. 1984)

En Jung, los métodos de interpretación (de los sueños) se vinculan con:

- Es una herramienta de autoexploración de la mente inconsciente que nos habla en un lenguaje de símbolos, y que exige la decodificación de los mismos.

- Hacer asociaciones relacionadas con los símbolos (escribiendo cada una de las imágenes), y luego narrando que asociación surge con respecto a cada una. Las asociaciones correctas para cada elemento son aquellas que el ser humano siente como tales (causan una reacción), y tienen sentido en la vida.

- Conexión de imágenes del sueño con aspectos internos del ser. A partir de las asociaciones y de la identificación a que parte corresponde cada elemento y representan una cualidad, acción, estado emocional o concepto.

- Cuestionar el mensaje del sueño, elaborando una lista a partir de las cuales, seleccionar una (que guía la interpretación de algo que no se sabe).

- El nuevo conocimiento debe anclarse con un ritual o acción que indique la comprensión del mensaje.

Vechis (2018) presenta un estudio sobre los textos de Jung y de comentaristas de él en el análisis de categorías obtenidas con la investigación: “el término "hermenéutica” en la Psicología de Jung”, "la epistemología ese in anima", "la actitud simbólica", "las cuatro etapas de lectura", "la orientación teleológica en la comprensión de sentido" y "el discurso y el iconográfico como material empírico en la hermenéutica junguiana". Se aplicaron procedimientos de esta hermenéutica tales como: "la actitud simbólica del investigador: circunscribir la realidad como símbolo"; "la epistemología ese in anima; "los símbolos discurso e iconográfico de individuos, grupos o culturas como material empírico; "la comprensión del 
símbolo como medio de investigar un tema/problema de estudio"; "la lectura del símbolo mediante los procedimientos 'dejar que suceda, 'concebir y objetivar' y 'confrontarse con y diferenciarse de' y “'amplificación"” y "la perspectiva finalista que prioriza la identificación de propósito y propósito en lugar de causa y de explicación en el proceso de comprensión del símbolo”.

De la Psicología a la Antropología media un paso (Ortíz Oses, 1983), ya que muchos de los conceptos desarrollados en el modelo de Jung, sirven para interpretar la cultura a partir de cinco niveles psíquicos: nivel incestuoso, de distinción, de autoafirmación, de reconocimiento de valor y de reconciliación. La idea es que para interpretar cualquier relato, tener en cuenta una jerarquía de procesos de individualización. Por otro lado, los símbolos son ambivalentes, condensan energía psíquica (por lo tanto es una amplificación de la libido). Esa amplificación debe unirse con la comparación que ayuda a la contextualización. Y vale decir: la subsunción de métodos llevó a la conformación de la Antropología Hermenéutica. (Ortíz Oses, 1986; Ortíz Oses y Lanceros, 2006).

Solares Altamirano (2012) analiza el trabajo de Mircea Eliade como hermeneuta de la Historia de las Religiones y los mitos sobre los conceptos del "homo symbolicus" y "religiosidad", resaltando del autor:

El estudio "comparado" de la religión dice: estudio de la "morfología cambiante de lo sagrado"; estudio de lo sagrado en su transformación histórica. Cada documento (objeto, rito, mito, oración, vestido del chamán) es una hierofanía en un doble sentido: en cuanto revela una modalidad de lo sagrado; y, en cuanto revela un momento de su historia, una experiencia de lo sagrado entre innumerables existentes. Lo sagrado se manifiesta en una cierta situación histórica. Lo que no quiere decir que una experiencia religiosa, es decir una hierofanía, sea un momento único y sin repetición posible en la economía del espíritu. El hecho de que una hierofanía sea histórica, no destruye su ecumeneidad (Solares Altamirano, 2012: 39).

La investigación de López Austin (1995), introduce un marco de análisis interpretativo a través del uso de la comparación de los mitos entre las cosmovisiones mesoamericana y andina. En Vergara Silva, F., Yáñez Macías V. y Roger Bartra, B. (2016), el habla, la música y el arte, es introducido como una prótesis de expresiones exocerebrales "primitivas", susceptible de ser interpretado.

\section{Hermenéutica Analógica}

Para Mauricio Beuchot, la Hermenéutica Analógica tiene sus fuentes en pensadores mexicanos, tanto como universales, dando el caso de Bartolomé de las Casas en su intención de comprender la cultura indígena mediante analogía griega y romana (entre otros) y llegando al siglo pasado bajo los nombres de Octavio Paz, Adolfo García Díaz y Enrique Dussel (con distintas aplicaciones sobre la analogía) (Conde Gaxiola, 2004).

Desde su obra "Tratado de Hermenéutica Analógica. Hacia un nuevo modelo de interpretación" (2000), desarrolla la constitución y método de la Hermenéutica, Ontología y Hermenéutica Analógica en Filología Clásica y Epistemología del Psicoanálisis y Ética e introduciendo el análisis del acto hermenéutico dónde intervienen el texto, el autor y el lector. Los estudios de Hermenéutica Analógica se engarzan con los estudios de la Filosofía del Lenguaje (Beuchot, 2011).

El acto interpretativo conlleva a una serie de preguntas: ¿qué significa el texto?, ¿qué quiere decir?, ¿a quién está dirigido?, ¿Qué me dice a mí?, luego la pregunta es un juicio prospectivo, la misma se 
resuelve primero convirtiéndola en hipótesis y después en tesis. Se puede entender como un argumento abductivo (Pierce) o de conjetura y refutación (Popper), utilizando los modus tollens y ponens de la lógica para llegar a una inferencia.

El paso siguiente es introducir la noción de analogía y de Hermenéutica Analógica como modelo teórico de interpretación, con sus propios aspectos ontológicos y epistemológicos. La adecuación con la verdad de la traducción y de la interpretación se da de manera aproximada e intersubjetiva, con pretensión a acercar comprensión con explicación. Y todo esto, desde una perspectiva interdisciplinar, de tal manera que aquí tienen cabida trabajos de Filosofía, Pedagogía, Sociología, Política, Psicología, Antropología, Arquitectura, Arte, en lo fundamental, realicen una interpretación icónica-analógica del fenómeno abordado.

En la Historia de la Lógica y de la Filosofía del Lenguaje la analogía se define como un modo de significar y de predicar (es decir, de atribuir predicados a un sujeto) a medio camino entre la univocidad y la equivocidad. La analogía es la significación de un término en relación con sus significados en parte idéntica y en parte diferente. De la trayectoria de la historia de la analogía, a Beuchot le interesan particularmente los estudios de Pierce.

La analogía será tomada por Pierce a través de tres elementos: - El índice es el signo unívoco, porque es natural, surge de una relación de causa y efecto, como la huella en el lodo y el animal que la imprimió. El símbolo es el signo equívoco porque es cultural, como el lenguaje, en el que una cosa (como la mesa) se dice de maneras diferentes en los distintos idiomas. En cambio, el ícono es en parte natural y en parte cultural, en parte idéntico y en parte diferente, como un simulador de un avión, donde se aprende a pilotear. Además, Peirce divide el ícono en tres: imagen, diagrama y metáfora. La imagen nunca es unívoca, es decir, idéntica a lo representado; es sólo semejante. La metáfora también ofrece conocimiento. Y el diagrama está entre la una y la otra, pudiendo ser desde una fórmula algebraica hasta una buena metáfora (Beuchot, 2015: 135)

Posteriormente ejercerán influencia en Beuchot los lógicos polacos de la Escuela de Innocentius (entre ellos M. Bochenski) y los trabajos de Ricoeur. Beuchot entiende a la Hermenéutica Analógica como un instrumento de interpretación de textos, como también en una epistemología de las virtudes epistémicas (prudencia, equilibrio proporcional y sabiduría), desde dónde arrojar luz sobre la práctica. La Hermenéutica Analógica trata de evitar los extremos (hermenéutica univocista que sólo acepta una única interpretación como válida y todas las demás las considera inválidas o inadecuadas; y equivocista que considera válidas casi todas las interpretaciones, si no es que todas, alegando que no hay criterios claros para decidir cuándo una interpretación es adecuada y cuándo no).

La Hermenéutica Analógica emplea dos formas de analogía: la de proporcionalidad y la de atribución:

En su aspecto de proporcionalidad, es capaz de aglutinar, conmensurar o coordinar varias interpretaciones de un texto por lo que tienen de común, es decir, busca el común denominador de éstas, a pesar de las diferencias que contienen. Iguala en lo posible; es la parte de identidad que tiene la analogía o semejanza. En su aspecto de atribución, es capaz de distinguir, atiende las diferencias y, aprovechando su estructura jerárquica, nos ayuda a disponer de las varias interpretaciones de un texto de manera ordenada, según su mayor o menor adecuación al significado del texto. De modo que se puede establecer cuáles interpretaciones son los analogados principales 
y cuáles los secundarios"(...) "la analogía de atribución se divide en intrínseca y extrínseca, de modo que habrá niveles de interpretación que serán muy apegados al significado del texto, de manera intrínseca y esencial, dando paso a una idea de verdad como correspondencia o adecuación, y otras de manera extrínseca y accidental la analogía de proporcionalidad se divide en analogía de proporcionalidad propia y analogía de proporcionalidad impropia o metafórica (Beuchot, 2015: 137)

Por lo tanto, resulta que la analogía puede abarcar metáfora y metonimia, lo que permitirá interpretaciones sintagmáticas tanto como paradigmáticas, unas más superficiales (en el sentido literal) y otras en mayor profundidad (en el sentido metafórico).

En el ámbito de la aplicación, el símbolo es privilegiado (y sobre todo en Antropología), y desde la Hermenéutica Analógica particularmente se utilizará tanto en el sentido literal (manifiesto) como analógico (latente), con el límite de buscar el sentido de los textos, tanto como su referencia.

En toda interpretación, la Hermenéutica Analógica será tanto sintagmática (plano horizontal y superficial del lenguaje ordinario) como paradigmática (plano vertical y en profundidad del lenguaje ordinario), el entrecruzamiento entre ambos sería la diferencia: entre oposición (presencia) y memoria (ausencia), procediendo la asociación, dónde lo que se repite es diferente y al mismo tiempo análogo. A esa diferencia se llega mediante el diálogo entre extremos, lo que permite ampliar la gama de interpretaciones evitando los dilemas (contradicciones o problemas).

En resumen:

La hermenéutica analógica, una teoría de la interpretación que trata de colocarse entre una hermenéutica unívoca, que pretende interpretaciones claras y distintas, rigurosas y exactas, de los textos (cosa que creo que en las humanidades no se puede alcanzar), pero que también trata de evitar la hermenéutica equívoca, la cual se hunde en un mar de interpretaciones oscuras y confusas, irremediablemente ambiguas e inexactas, y que produce un relativismo excesivo en la comprensión (Beuchot, 2015:137)

La Hermenéutica Analógica se ha integrado como instrumento conceptual en el estudio del mito, la cultura y el multiculturalismo (Beuchot, 2006; Alvarez Balandra, A. C.; Beuchot, M. y Alvarez Tenorio, V.:2018) y de la Educación Intercultural. Desde el punto de vista metodológico, se aceptan etapas o fases comúnmente aceptadas, (Manchado Villoria, 2017), a saber:

- El establecimiento de un conjunto de textos, normalmente llamados cánones, para interpretarlos;

- La interpretación de esos textos,

- La generación de teorías sobre los literales a y b.

La primera etapa corresponde al nivel empírico y la segunda y tercera al nivel interpretativo. La investigación suele surgir a partir de un examen de la bibliografía ya expuesta en párrafos anteriores y la identificación de un problema. Éstos se explican para generar una interpretación, la relación de la nueva con las existentes (la dialéctica comunal) y la diseminación a un amplio número de lectores.

\section{Hermenéutica Objetiva}

La Hermenéutica Objetiva es actualmente uno de los enfoques más prominentes en la investigación 
cualitativa en países de habla alemana, incluidos Austria y Suiza. Uno de sus mayores inconvenientes de su difusión ha sido el uso del habla alemana en todos sus debates.

La Hermenéutica Objetiva, siguiendo a Teixeira Vilela, R. y Noack-Napoles, J. (2010) se deriva de la tradición interpretativa de la Teoría Crítica de Theodor Adorno y puede aplicarse a textos escritos de protocolos de investigación de campo, entrevistas, así como obras de arte, música, arquitectura son igualmente textos a interpretarse.

Siguiendo a Reichrtz (2004), el término Hermenéutica Objetiva proviene del trabajo de Ulrich Oevermann (y de sus investigaciones conjuntas con Krappmann y Kreppner desde 1068), pero también puede rastrearse bajo las denominaciones de Hermenéutica Estructural o Estructuralismo Genético. A fines de los 60, los estudios se inclinaban a analizar cuatitativamente la importancia de los códigos lingüísticos restringidos y elaborados para el rendimiento escolar.

En la década siguiente trabajaron en el desarrollo de procedimientos de recopilación de datos cualitativos y también sobre procedimientos analíticos hermenéuticos. El nuevo enfoque se estableció, metodológicamente con referencia a la teoría del lenguaje de Mead, el concepto de reglas de Searle y la lógica de investigación abductiva de Peirce.

En la década siguiente, la Hermenéutica Objetiva se ha preocupado en el uso de conceptos teóricos, consultoría práctica y temas políticos actuales, tales como la teoría de las profesiones, el concepto de estructura, la crítica de los medios de comunicación, el significado de la religión, el desarrollo de la innovación, y con problemas en la interpretación de pinturas.

La Hermenéutica Objetiva pretende ser el método fundamental de investigación para todo tipo de investigación sociológica, interpretando protocolos de interacción cotidiana, textos, pintura, arquitectura, (entendiéndolas como textos). El procedimiento consiste primero en concebir y fijar la acción social en cuestión como un texto, para posteriormente interpretarla hermenéuticamente con respecto a las estructuras de significado latente generadoras de acción.

La propuesta de Oevermann se sustenta en que no existe un único procedimiento para la interpretación objetiva de los textos, se trata más bien de un entendimiento básico dónde se tienen en cuenta: - El análisis lleva mucho tiempo; - hay que asegurarse de que los intérpretes sean miembros competentes de la comunidad lingüística e interactiva que se está investigando; y la posibilidad de utilizar tres formas de presentación de la propia práctica de la investigación (o tres variantes de explicación del texto).

1-El análisis detallado de un texto a ocho niveles diferentes, en el que el conocimiento y el contexto externo, y también los pragmáticos de un tipo de interacción, se explican de antemano y se tienen en cuenta en el mismo.

2 -El análisis secuencial de cada contribución individual a una interacción, paso a paso, sin aclarar de antemano el contexto interno o externo de la expresión. Ésta es la variante más exigente de la Hermenéutica Objetiva, ya que está muy orientada hacia las premisas metodológicas del concepto global. Los textos se interpretan en detalle paso a paso sin utilizar ningún conocimiento del caso

3-La interpretación completa de los datos sociales objetivos de todos los que participaron en una interacción, antes de que cualquier enfoque se hace al texto a ser interpretado. Esta variante maneja los fundamentos de una teoría de la interpretación hermenéutica de manera muy flexible y los utiliza de una manera algo metafórica. Sitúa la explicación de los datos de casos objetivos antes del análisis del texto.

Siguiendo con la variante segunda, sólo realiza análisis de un solo caso, la recopilación de datos no normalizados y su análisis hermenéutico objetivo garantizarían resultados válidos. La Hermenéutica Objetiva procede del singular (reconstrucción de la estructura de los casos individuales) a la afirmación 
general (generalización de la estructura) mediante el principio de falsación. Una estructura de casos, una vez reconstruida, puede utilizarse en la interpretación de otros ejemplos del mismo tipo que una heurística.

En síntesis, en el desarrollo del análisis de texto hay una reconstrucción de la estructura que se encuentra en el texto bajo investigación. Esta descripción debe ser lo más precisa y distintiva posible. Si, en el curso del análisis del texto, se puede encontrar un lugar que contradiga la descripción estructural previamente descrita, entonces se puede decir que la hipótesis ha sido falsificada.

En términos metodológicos, la lógica de la investigación se centra en:

1- $\quad$ Fase de entrada, el protocolo de datos se somete a una codificación abierta, lo que significa que el documento en cuestión se analiza secuencialmente, ampliamente y en detalle, y de hecho línea por línea o incluso palabra por palabra. Lo decisivo en esta fase es que no se apliquen lecturas (preexistentes) al texto, sino que el investigador construya tantas lecturas como sea posible que sean compatibles con el texto. El tipo de interpretación requiere que el intérprete rompa repetidamente tanto los datos como los prejuicios (teóricos) y evaluaciones, y esto crea un clima saludable para el descubrimiento de nuevas lecturas. Se busca en esta codificación abierta unidades de significado que contienen conceptos teóricos y que se refieren a estos.

2- $\quad$ Fase de la interpretación lo que se busca son unidades de significado más altamente agregadas y conceptos que unen las unidades parciales individuales. Se pueden definir razones para volver a recoger determinados datos o en mayor detalle.

3- $\quad$ Fase de producción de nuevos protocolos de datos de una manera más específica. La interpretación controla la recogida de datos, pero al mismo tiempo es falsificada, modificada y ampliada mediante la posterior recogida de datos.

4- $\quad$ Fase de construcción de un concepto o configuración de significado altamente agregado, en el que todos los elementos investigados pueden integrarse en un todo significativo y cuando este todo se ha hecho inteligible (es decir, significativo) en el contexto de una comunidad de interacción particular.

Gürtler y Huber (2007) sostienen que el análisis de secuencias no es sencillamente un instrumento del análisis de datos, sino una estrategia de investigación o una metodología distinta. La meta del enfoque es la "reconstrucción estructural-lógica" de estructuras latentes y sentidos de "textos" (conversaciones, entrevistas, fotos, grabaciones de sonido o video, dónde todo el mundo social tiene la forma de texto). Describen metodológicamente a la hermenéutica objetiva como aquella reconstrucción del error previene el falseamiento. Se analiza textos por secuencias y trata de formular una hipótesis (basado en la pregunta de investigación) respecto a su continuación. Esta hipótesis se tiene que comprobar estrictamente con los datos del texto. El intercambio permanente entre formular y comprobar hipótesis lleva a la (re)construcción de una primera estructura hipotética del caso. Se continúa el análisis de secuencias hasta que se encuentra la estructura hipotética otra vez. Ahora se busca segmentos de texto que podrían servir para probar lo contrario, es decir, que se podrían "leer" como o interpretar como contradicción de la estructura hipotética. En caso de falsación, el error sirve para probar la hipótesis, se acepta que la hipótesis estructural explica el caso y se habla desde este punto de la estructura del caso.

Son consideradas como reglas determinan el proceder del análisis de secuencias:

- Interpretación al pie de la letra, (los modos distintos de leer el texto) dependen de lo que es dado literalmente en el texto, porque el texto mismo es una parte de la realidad.

- Consideración de la secuencia, es decir se trabaja estrictamente y paso por paso según la estructura del texto desde el comienzo hasta el final. 
- Análisis extensivo, es decir lo que cuenta es la totalidad del texto como objeto de la investigación

- Economía, es decir se parte del caso normal.

- El análisis de secuencias no solamente vale para analizar textos, sino también organigramas, genogramas y otros datos estructurales.

Decir que el análisis debe ser estrictamente secuencial es decir que hay que seguir el curso temporal de los acontecimientos en el texto. Flick (2009), describe todo el proceso investigativo propuesto por Oevermann como sigue:

- Explicación del contexto que precede inmediatamente a una interpretación.

- Paráfrasis del significado de una interacción de acuerdo con el texto literal de la verbalización que la acompaña

- Explicación de la intención del sujeto que interactúa

- Explicación de los motivos objetivos de la interacción y de sus consecuencias objetivas

- Explicación de la función de la interacción por la distribución de los roles en la interacción

- Caracterización de los rasgos lingüísticos de la interacción

- Exploración de la interacción interpretada por figuras comunicativas constantes

- Exploración de las relaciones generales

- Prueba independiente de las hipótesis generales que se formularon en el nivel anterior a partir de las secuencias de interacción de casos posteriores (Flick, 2009:223).

En este análisis fino secuencial, la interpretación se observa en todos los procesos que involucran narraciones de relatos sobre todas las situaciones de contraste posibles que encajan de manera coherente en una declaración, y en los experimentos mentales, dónde los intérpretes analizan las implicancias de las declaraciones examinadas, y dónde las opciones posibles encontradas sirven como una transparencia de contraste para especificar la declaración siguiente que realmente sucedió. La idea es que la estructura del caso va manifestándose gradualmente y se generaliza sometiéndola a prueba frente a otros casos.

Siguiendo a Relchertz, sobre la lógica de la investigación en Hermenéutica Objetiva:

La Hermenéutica Objetiva procede del singular (reconstrucción de la estructura de los casos individuales) a la declaración general (generalización de la estructura) mediante el principio de falsificación; la reconstrucción de la estructura y la generalización de la estructura se conciben como los polos exteriores de un proceso de investigación dirigido en el que los resultados de una serie de reconstrucciones estructurales de un solo caso se condensan en una estructura más general. Una estructura de casos, una vez reconstruida, puede utilizarse en la interpretación de otros ejemplos del mismo tipo que una heurística que debe falsificarse". (...) "El objetivo de la generalización estructural es siempre el descubrimiento y la descripción de casos generales y casos específicos de la regla-gobernabilidad, las llamadas reglas generativas que, según Oevermann (1999a), tienen un estado comparable a las leyes naturales y hechos naturales. Con la ayuda de este conocimiento positivo de los pronósticos generales y únicos para el futuro de un sistema de acción. Las declaraciones deterministas precisas son, sin embargo, imposibles: sólo se puede indicar el alcance de las transformaciones (Relchertz, 2004: 292)

Y remarca, en la actualidad el enfoque que más la utiliza es la Sociología del Conocimiento, en el sentido de que ha investigado la cuestión principal de cómo los sujetos de acción por un lado (tienen que) 
localizarse y adaptarse de una manera adecuada y socializada en las rutinas y significados de un campo de acción particular, desarrollados histórica y socialmente; y cómo, ellos (deben) constantemente reinterpretarse e inventarse a sí mismos individualmente. Las nuevas (es decir, constituidas de acuerdo con las relevancias del sujeto de acción) reinterpretaciones del conocimiento socialmente interpretado, por su parte, se introducen entonces (también como conocimiento) en el campo de la acción social.

\section{Hermenéutica y Ciencias Sociales}

Rivas y Briseño (2012) deslindan los caminos de la Hermenéutica, sus ideas y fines originarios, desarrollo a lo largo del tiempo, fortalezas y debilidades en la época del posmodernismo. También distinguen tipos fundamentales de interpretación:

- Interpretación intransitiva meramente recognitiva (filología e historia), en donde el entender es fi n en sí mismo.

- Interpretación transitiva reproductiva o representativa, es decir, traductiva (drama, música), ej. la que se trata de hacer entender.

- Interpretación normativa o dogmática (jurídica y teológica) en la que entra en juego la regulación del obrar.

A nivel metodológico diferencian:

Tres etapas principales y dos niveles. Las etapas son: a) el establecimiento de un conjunto de textos, normalmente llamado "canon", para interpretarlos; b) la interpretación de esos textos, y c) la generación de teorías sobre los literales a y b. La primera etapa corresponde al nivel empírico y la segunda y tercera al nivel interpretativo. La investigación suele surgir a partir de un examen de la bibliografía y la identificación de un problema. Así pues, los pasos más relevantes en toda investigación hermenéutica son: a) la identificación de algún problema; b) la etapa empírica que incluye la identificación de textos relevantes y su correspondiente validación; c) la etapa interpretativa en la que se buscan las pautas en los textos. Éstos se explican para generar una interpretación, la relación de la nueva con las existentes (la dialéctica comunal) y la diseminación a un amplio número de lectores (Rivas y Briseño, 2012: 231).

Arráez, M.; Calles, J. y Moreno de Tovar, L. (2006) presentan una serie de categorías a tenerse en cuenta en una investigación ubicada en el paradigma cualitativo y documental que tiene como objetivo el análisis de la Hermenéutica como una actividad interpretativa para abordar el texto oral o escrito.

Para Mantzavinos, C., (2016) la Hermenéutica como metodología de interpretación se refiere a los problemas que surgen cuando se trata de acciones humanas significativas y los productos de tales acciones, sobre todo los textos. Como disciplina metodológica, ofrece una caja de herramientas para tratar eficientemente los problemas de la interpretación de las acciones humanas, textos y otro material significativo.

Dentro del recorrido histórico de la hermenéutica destaca el surgimiento en la Edad Antigua, su tránsito por la Edad Media, las discusiones en torno al Círculo Hermenéutico a partir de Friedrich Ast (en cuanto a la circularidad en la interpretación) o como cuestión ontológica en Heidegger. Paso siguiente: la interpretación del texto va más allá de la interpretación de frases simples o complejas, ya que incluye de manera crucial una serie de inferencias que son necesarias para captar el significado de un texto. 
La interpretación del texto como una actividad orientada a objetivos puede adoptar diferentes formas, pero debe distinguirse de la importancia de un texto. La aplicación del método hipotético-deductivo en el caso de material significativo se ha propuesto como una forma plausible de explicar la actividad epistémica de la interpretación de textos. Comenzando desde los debates sobre la relación con la teoría filosófica de la explicación científica y la actividad científica como una actividad exclusivamente explicativa, en gran parte destinada a responder "¿por qué?", con Hempel y Popper. social:

Cárcamo (2005), introduce elementos para una praxis hermenéutica en el quehacer investigativo

1) Lograr un conocimiento acabado del contexto en el cual es producido el discurso sometido a análisis. 2) Considerar la frase o la oración como unidad de análisis en el corpus. 3) Trabajar analíticamente apoyándose en la malla temática y sus codificaciones respectivas. 4) Establecer un primer nivel de síntesis en el análisis de contenido. 5) Trabajar analíticamente por temas, desde la perspectiva del entrevistado. 6) Establecer un segundo nivel de análisis de contenido. 7) Trabajar analíticamente el conjunto de las entrevistas, desde las perspectivas de las personas sometidas a entrevista. 8) Revisar el análisis en sentido inverso, es decir comenzando esta vez desde la perspectiva del entrevistado.9) Establecer conclusiones finales según estrategia de análisis de contenido escogida (vertical u horizontal)(Cárcamo, 2005: 210).

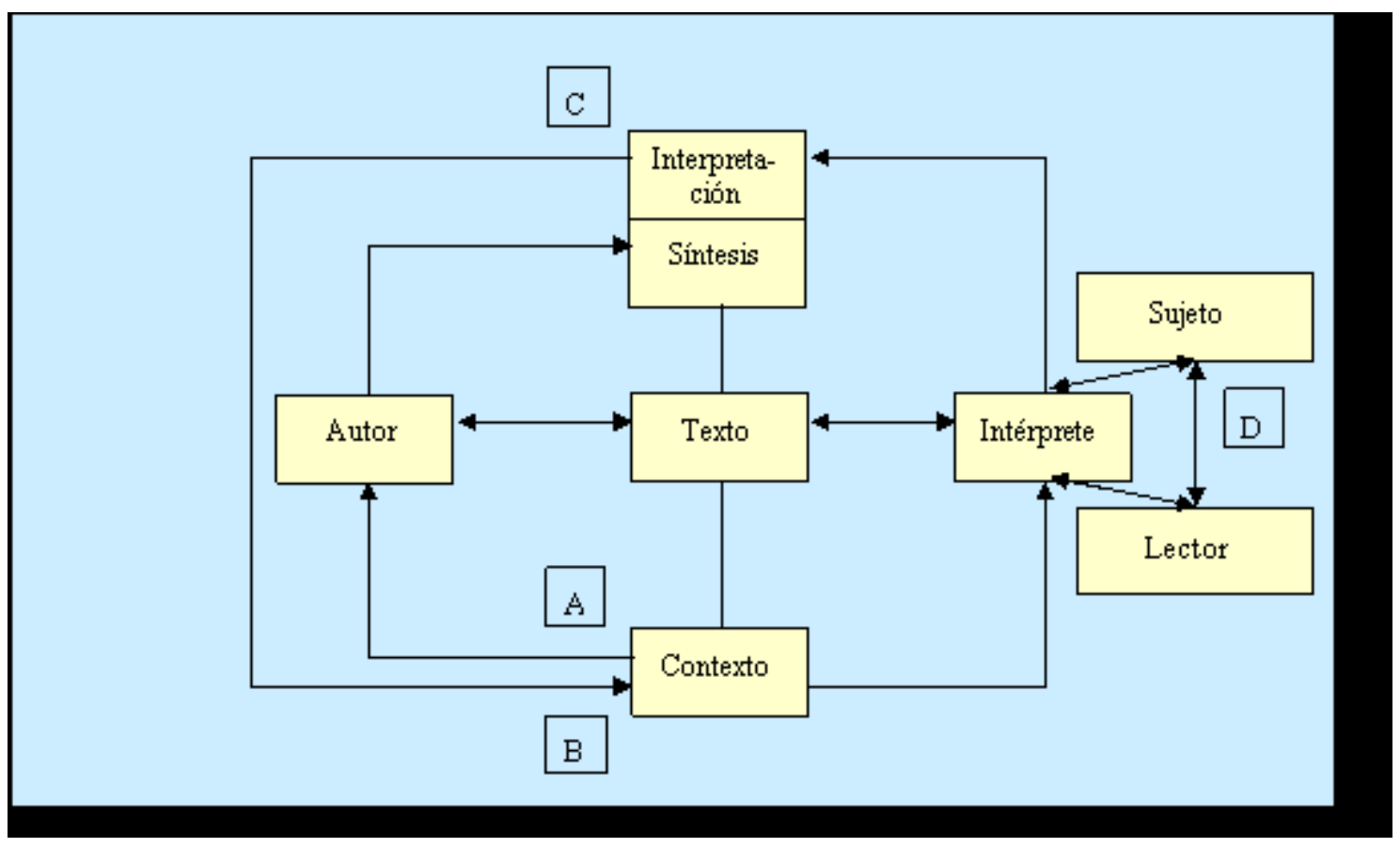

Fuente: Cárcamo, H. (2005). Hermenéutica y Análisis Cualitativo. Modelo propuesto por el autor

Siguiendo con el Modelo propuesto por Cárcamo: A (hace referencia al contexto del otro); B: (hace referencia al contexto propio); $\mathrm{C}$ : se refiere a que la interpretación debe ser considerada como propuesta que se apoya en la síntesis que se realizó previamente. D: se refiere a la consideración del intérprete en una doble dimensionalidad. La primera permite visualizarlo como sujeto con una serie de elementos valorativos -que trascienden los aspectos contextuales- y que harán operar la acción intencionada por parte de él. 
La segunda, hace alusión al intérprete lector cuyos esfuerzos podrán estar orientados a la captación del sentido primario dado por las estructuras gramaticales y el vocabulario utilizado para su configuración. Y, a su vez, tomando en cuenta cuatro estructuras fundamentales del proceso de intelección: Horizonte, circular, mediación y diálogo. Con respecto a la última estructura:

Se presenta como requisito fundamental la voluntad de apertura del sujeto cognoscente hacia el o los otros con la intencionalidad focalizada de comprender sus palabras. Esta intencionalidad, puede expresarse de dos formas; la primera de éstas es la presencial hablada por lo tanto sincrónica y la segunda es la de lectura reconociendo el distanciamiento con el sujeto que interpretó y que nosotros estamos interpretando, por tanto diacrónica (Cárcamo, 2005: 215).

Pérez (2011) indica la lectura de siete perspectivas metodológicas cualitativas en las Ciencias Sociales a partir de las claves que ofrece la filosofía hermenéutica: Fenomenología, Teoría Fundamentada, Estudio de caso, Etnografía, Investigación Acción Participativa, Cartografía Social y la Investigación Narrativa. El autor, más allá de asegurar cada tradición con una disciplina de las Ciencias Sociales, se hace eco de la propuesta de Denzin y Lincoln, quienes consideran las metodologías cualitativas como bricolage, y al investigador como bricoleur, y admiten que las herramientas utilizadas pueden ser múltiples y se puede echar mano de cualquier método, mientras se conserve el rigor en el análisis y no se pierda de vista el objeto estudiado.

En cuanto a los estudios de caso, sigue el planteamiento de Robert Stake (1999) quien diferencia a aquellos considerados en sí mismos (estudio de caso intrínseco); de aquellos que se usan para ahondar en un tema o confirmar una teoría (estudios de caso instrumentales), y de los que buscan establecer regularidades en una población (estudio de casos colectivos). Los casos deben ser limitados en número y si se busca representatividad se requiere una muestra de un número representativo de individuos de una población que permita establecer regularidades. En la perspectiva de Stake hay elementos que la acercan a los postulados hermenéuticos, puesto que el interés se centra en el caso, que la explicación de éste no se remite a una teoría con pretensiones de universalidad y asume una ética de la interpretación como la forma de aproximarse a los hechos.

En cuanto a la Teoría Fundamentada:

Es definida por Strauss y Corbin (2002) como un método de análisis cualitativo de los textos escritos, obtenidos como resultado de entrevistas en profundidad o semiestructuradas. Se utilizan también observaciones directas que pueden ser registradas en video o en fotografía y que, en cualquier caso, deben tener un registro escrito. Esta definición indica que la teoría fundada tiene un énfasis especial en el procedimiento, tanto en el proceso de obtención de los datos como en su codificación en palabras de los incidentes recogidos en el proceso. Esta codificación en palabras claves permite posteriormente agrupar los datos en categorías, conceptos o constructos para establecer semejanzas y diferencias entre las categorías identificadas. De ahí la necesidad de definir con claridad el término categoría que va a permitir finalmente hablar de teoría (Pérez, 2011: 15).

La propuesta de la Teoría Fundada se relaciona con la Fenomenología el poner entre paréntesis la carga del sujeto y dejar que la cosa hable. Todo proceso de teorización se efectúa a partir de la definición de conceptos de acuerdo con sus dimensiones (ordenamiento conceptual), siendo ellos mismos la intensidad que una persona le adjudica a una ocurrencia y la frecuencia con la que ésta sucede. Debe sumarse la noción de Muestreo Teórico (logrado por saturación de las categorías investigadas) y la aplicación del Método de Comparación Constante (que conecta campo con datos y análisis), y se repiten estas operacio- 
nes, lo que tiene un parecido de familia con el "círculo hermenéutico" en términos de Heidegger.

En el caso de la Fenomenología, se trata de principios metodológicos que debieran considerarse en una investigación. El método fenomenológico implica:

1. El investigador explicita las perspectivas filosóficas de su aproximación, orientadas a percibir la manera como la gente interpreta un fenómeno (concepto de epokhé). 2. El investigador se hace preguntas que le permitan explorar el significado de la experiencia para quienes la viven. 3. Se reúnen datos de quienes han experimentado el fenómeno en el proceso de investigación (el instrumento preferido es la entrevista en profundidad). 4. Los protocolos originales se dividen en declaraciones o afirmaciones horizontales. Después, las unidades son transformadas en núcleos de significados expresadas en conceptos psicológicos y fenomenológicos. Finalmente, estas transformaciones son agrupadas para hacer una descripción general de la experiencia, la descripción textural sobre lo que se ha experimentado y la descripción estructural de cómo fue experimentado. 5. El informe concluye cuando el lector comprende la esencia de la experiencia, reconociendo que existe un significado unificador de dicha experiencia (Pérez, 2011: 19).

La Investigación Etnográfica, que tiene su origen en la Antropología Cultural a principios del siglo $\mathrm{XX}$, y se centra en el interés por la cultura y con respecto a la Etnografía en determinar aspectos que se observan: artefactos, costumbres y lenguaje. Se acerca a la Hermenéutica en los trabajos de Clifford Geertz bajo la noción de "giro interpretativo", con predominio del lenguaje en la atención de los científicos. Todo esto plantea la posibilidad de diálogo entre culturas y su comprensión, cuando descifrar el pensamiento local se construye con una Hermenéutica Cultural.

La Teoría de la Acción Participativa, surgida en los años 70, es una postura investigativa íntimamente ligada a la vida social en una perspectiva emancipatoria es una perspectiva dialógica, que requiere un proceso interpretativo. En términos de Fals Borda, es un llamado a la construcción de un ethos etnogenético que hace referencia a la multiplicidad, al diálogo entre diferentes y a la búsqueda de la emancipación que permita enriquecer las culturas de toda la humanidad. Es una tarea hermenéutica por excelencia, ya que implica el diálogo intercultural y proyectivo que exige la interpretación

La Cartografía Social, es un derivado de la Teoría de la Acción Participativa, de la Cibernética y del Socio-análisis. Son importantes los conceptos de: el territorio es un fluido de información y de energía, de tal modo que en los mapas sociales se trazan líneas y representaciones del espacio local concebido como un sistema de comunicación; mapa de relaciones y estructuras de poder que determinan las interacciones entre los distintos agentes, instituciones y grupos sociales y del territorio social cruzado por el deseo de cambio de los agentes que intervienen en el espacio local.

El territorio se renueva o se deteriora continuamente y está cruzado por fuerzas simbólicas producidas por los actores sociales que lo ocupan; es un espacio de escritura del tiempo. En él se sintetiza la historia de los conflictos, las resistencias y los deseos que inscriben los agentes que viven esa historia. El mapeo como ejercicio de representación del espacio como síntesis del tiempo. A nivel metodológico:

El primer momento implica la selección del espacio físico que se pretende trabajar, que debe estar ligado, de alguna manera, a un proceso de identidad colectiva. Se define el alcance del estudio (institucional, local, municipal, etc.). Se establecen los recursos físicos y humanos para el estudio y, finalmente, se considera en este momento la ampliación del campo de visión y de comprensión del territorio por parte de los investigadores, y la identificación de los diversos grupos (formales e informales) en el territorio. El segundo momento, la elaboración de los mapas, puede partir del levantamiento de un diagrama topográfico del territorio, y se trabaja con cuatro 
categorías que organizan las discusiones de los actores: itinerarios, diagramas, representaciones y posiciones. Los itinerarios identifican los recorridos físicos de los actores que cruzan el territorio. Los diagramas se refieren a una geografía abstracta de esos itinerarios, y busca identificar clases de rutinas que presenten rasgos comunes en el uso del territorio. Las representaciones avanzan en abstracción y tratan de identificar posiciones simbólicas presentes en el espacio social. (...) el tercer momento se refiere a la reflexión sobre el territorio a partir del mapa elaborado y la construcción de un plan de acción o de alternativas de solución. Una vez realizado el primer mapa que contiene las líneas descritas como tendencias, surge un segundo mapa. El primer mapa define el territorio, lo delimita, lo configura. El segundo mapa conduce a preguntas útiles para negociar un derrotero de acción de los agentes. Este segundo mapa abre un espacio de enunciación para los actores, que es un espacio de formulación y negociación de propuestas (Pérez, 2011: 28-29).

En las Investigaciones Narrativas, a nivel metodológico debe considerar el uso de herramientas como entrevistas en profundidad, grupos focales y observación directa.

En segundo lugar, debe describirse la metodología del análisis de esas narrativas mediante otras herramientas que pueden ser el Análisis Semiótico, el análisis de Contenido o el Análisis Crítico del Discurso Narrativo, de manera que se llegue por este medio al verdadero contenido que es la concepción de democracia que circula en ese grupo.

En esta perspectiva, se hacen estudios de representaciones sociales sobre algo o imaginarios de algo, y se supone que la representación o el imaginario no son la narración, sino su contenido. La narración es pensamiento y constituye la forma y el contenido de lo que una cultura piensa de sí misma. Si las narrativas se toman como objeto de estudio, lo que importa es la narrativa misma, desprendida de quien la narra y de su proceso de construcción. Lo que se estudia en este caso es una fábula o una leyenda o unas narraciones orales o escritas, a las cuales pueden aplicarse metodologías de análisis semiótico o de cualquier índole. Los relatos son, pues, autocomprensión que opera en la vida, son susceptibles de ser interpretados. Pero la interpretación como traducción de los relatos hace parte de otro proceso que es el diálogo con otras etnias, que genera procesos en el grupo donde nacen los relatos y en los otros grupos.

\section{Arqueología y Hermenéutica}

El término de "interpretación” en Arqueología, pueden asociarse a distintos niveles tanto teóricos como vinculados a la práctica (o a nivel metodológico). La primera dificultad en el análisis es intentar delimitar en qué nivel de discusión se sitúan las aproximaciones al tema. Le proponemos al lector las siguientes categorías:

Nivel $\mathrm{N}^{\circ}$ 1: Problemas de interpretación a nivel teórico/epistemológico

Alvarez Vidaurre (2007), centra su interés en la necesaria relación entre interpretación en Arqueología y Epistemología. Se refiere a corrientes interpretativas, como teorías generales o ideas genéricas sobre el cambio cultural en Prehistoria, que tienen como consecuencia directa la existencia de diferentes escuelas o corrientes de interpretación de las sociedades, cada una de las cuales predomina en una u otra línea metodológica (Positivismo Clásico, Escuela Histórico-Cultural, Procesualismo, Arqueología Contextual, Arqueología Postprocesual, Materialismo Histórico), aplicadas a la construcciones megalíticas. El foco de análisis lo constituye la interpretación posible, ya que: 
Así, al margen de haber tenido un origen concreto y un sentido inicial, tanto el fenómeno material en sí - la construcción megalítica-, como su significado, han ido siendo reinterpretados y reciclados con un sentido práctico que va ligado íntimamente a las circunstancias y la mentalidad propias de cada momento histórico. Estas construcciones se convierten en entidades polisémicas y cambiantes" (...)"Por ello, resulta de interés analizar la evolución en las formas de concebir y valorar el fenómeno megalítico a lo largo del tiempo, partiendo de la consideración de que además de objetos arqueológicos (restos de un momento temporal concreto), los megalitos han experimentado una rica vida posterior, que habitualmente no ha sido abordada por los prehistoriadores (Alvarez Vidaurre, 2007: 10)

Nivel $N^{\circ} 2$ : Problemas de interpretación a partir de diferenciación de enfoques descriptivos

González Ruibal (2012), se refiere a las arqueologías que adscriben a posturas histórico-culturales. Su propuesta es diferenciar la Arqueología puramente descriptiva frente a la Histórica Cultural propiamente dicha. En el primer caso, se preocupa por describir, ordenar y datar los restos materiales del pasado. En el segundo caso:

La arqueología propiamente histórico-cultural, en cambio, sí es interpretativa. Por lo general suele basarse en criterios evolucionistas y difusionistas más o menos intuitivos y simples, dado que rechaza la teoría social como una herramienta válida para pensar las sociedades documentadas a través del registro arqueológico (González Ruibal, 2012: 104).

Los nuevos escenarios de la Arqueología, en términos del autor deben pensarse en torno de una serie de propuestas de análisis: Una Arqueología sin límites temporales o multitemporal, participativa y pública, auténticamente política, creativa, con su propia retórica, que reivindica la materialidad, en pie de igualdad con otras ciencias, global, que sólo puede ser teórica.

La conclusión de este artículo es, inevitablemente, que la única arqueología posible para el siglo XXI es una arqueología teóricamente orientada, lo que quiere decir reflexiva, crítica, en diálogo con otras disciplinas y que se haga preguntas relevantes desde un punto de vista social y científico. Por un lado, conviene tener en cuenta que no se trata de filosofar o elaborar complejos modelos teóricos.” (...) "Lo importante es realizar una práctica conscientemente guiada por cuestiones teóricas y utilizar la teoría continuamente para generar nuevas ideas, interpretaciones y formas de ver el registro arqueológico" (Gonzáles Ruibal, 2012: 113).

Nivel N³: Problemas de interpretación disciplinar común

Vaquer (2015) analiza los puntos comunes entre tres disciplinas: Historia, la Antropología y Arqueología: la interpretación del pasado utilizando múltiples registros, que trascienden las disciplinas y los métodos particulares de cada una. También sostiene que la Hermenéutica es un marco propicio para desarrollar una Arqueología Dialógica que permita incorporar las interpretaciones del pasado de los grupos locales dentro de nuestro trabajo para mitigar la violencia epistémica inherente a las interpretaciones científicas. En cuanto a los vínculos entre Arqueología y Hermenéutica, la Arqueología post-procesual acudió a las ciencias humanas y sociales como teorías de alto rango para interpretar a las sociedades del pasado y cuestionar el rol de las interpretaciones en el presente. En una primera instancia, Ian Hodder 
$(1986,1995)$ propone que la arqueología contextual tiene sus conexiones más cercanas con la historia. Tomando como modelo los trabajos de Collingwood, sostiene que la arqueología es una disciplina hermenéutica que depende de la interpretación como herramienta principal. Si bien sus primeros trabajos fueron criticados por no tener en cuenta los desarrollos de la hermenéutica filosófica (principalmente los trabajos de Gadamer)" (...) "La incorporación de la hermenéutica en la teoría arqueológica tuvo al menos dos consecuencias importantes: la primera de ellas es que la interpretación depende de un intérprete, un sujeto que la realice" (...) "La segunda, vinculada con la primera, tiene consecuencias políticas: si la arqueología es interpretación, entonces el pasado es el producto de una interpretación situada en el presente. Esta postura, que considera a la arqueología como un discurso, fue profundizada por Shanks y Tilley (1987), quienes proponen que el pasado existe solamente como una narrativa que tiene efectos políticos en el presente; un discurso de poder que puede legitimar o cuestionar relaciones de poder existentes en el presente (Vaquer, 2015: 4).

Nivel N4: Problemas de Interpretación en Arqueología Histórica a nivel metodológico

Ramos (1999), analiza la implementación de información documental en el ámbito arqueológico:

En muchas ocasiones los arqueólogos hemos tomado los problemas vinculados a los sitios históricos como si fueran cuestiones que casi exclusivamente pasaran por la utilización y el rol de los documentos escritos o por las categorías, clasificaciones y la interpretación de la evidencia arqueológica obtenida". (...) "Entiendo que resultaría válido utilizar la información contenida en los documentos escritos para que a partir de ella pudiéramos plantear "hipótesis de partida" de una investigación (Ramos, 1999:63)

Nivel $N^{\circ}$ 5: Problemas de Interpretación en práctica situada específica

D’amore (2015), vincula la interpretación como estilo de deconstrucción de la idea de excavación como método científico a partir de dos categorías de pensamiento: la narrativa y la historicidad del método de excavación (como medida de control) de la profundidad que separa al pasado (interpretación de acontecimientos y situaciones) del presente en el registro y clasificación de testimonios materiales.

La excavación arqueológica está asediada por la selección de estrategias conceptuales para representar y explicar los datos, específicamente, en los términos de que los datos sean considerados información significativa para contribuir a contar una historia. En este contexto, la narrativa es identificada por el modo en que se manejan datos cualitativos, que marcan situaciones particulares en la construcción de historias acerca de un tema específico de una parte del pasado. La narración constituye un modo discursivo de presentación de los datos arqueológicos, conducida por una estructura verbal (oralidad) que va tomando forma en una prosa (escritura) y que puede surgir en cualquier momento del trabajo de campo, el laboratorio o en la preparación de cualquier texto de divulgación. La acción de narrar es un cimiento de la escritura de los distintos reportes de registro de excavación, puesta en evidencia por una aptitud narrativa hacia el registro arqueológico y la cultura material (D'amore, 2015: 503)

Lo susceptible de ser interpretado puede observarse en dos formatos: las hojas de día (registro diario escrito) y las planillas de registro de las unidades estratigráficas. En el primer caso, se trata de un documento que recaba información tanto del desarrollo de la excavación como de los materiales arqueológicos. No tienen esquema de registro prefijado, se representa la información utilizando dibujos, 
esquemas, números, colores y expresiones. El registro provee una lectura tanto de la información como del informante.

La información es múltiple: desde el detalle de los datos y las evidencias asociados a los hallazgos, las unidades estratigráficas y las relaciones entre ellos, hasta las diferentes interpretaciones que se van realizando, las discusiones y diálogos relativos a alternativas de registro, de procesos de formación, y de diferente criterios utilizados para la identificación y representación de las entidades arqueológicas de la excavación. Usualmente se repiten datos que ya fueron anotados en otras planillas de registro, a veces reforzando sus explicaciones; también se incluyen detalles y observaciones, algunos informales, que no tienen cabida en los esquemas pre-estructurados de los demás registros de excavación (D' amore, 2015: 504).

Del registro diario, una serie de instancias narrativas son susceptibles de ser analizadas:

dar órdenes y actuar siguiendo órdenes, describir un objeto por su apariencia o por sus medidas, construir un objeto de acuerdo a un esquema o dibujo, hacer conjeturas de un acontecimiento, relatar un suceso, desarrollar y comprobar hipótesis, imaginar una historia y comentarla, resolver un problema de matemática aplicada, comentar un chiste, completar la escritura de una planilla de registro, describir e interpretar la superposición estratigráfica y la depositación de ciertos hallazgos arqueológicos, diseñar el esquema o diagrama de una matriz de Harris, recriminar una acción indebida, manifestar un estado de ánimo particular, explicar un hallazgo arqueológico en relación con una tipología, tomar coordenadas de ubicación y cotas de profundidad de los hallazgos, entre otros (D' amore, 2015: 506).

Carbonelli (2011) señala en términos generales:

Siguiendo a Johnsen y Olsen (1992) sostenemos que uno de los aportes que puede brindarle la Hermenéutica a la Arqueología es cuestionarse sobre cuáles son las precondiciones necesarias para poder comprender el pasado (Carbonelli, 2011:5)

Y más específicamente ligado al registro:

Para poder aplicar un acercamiento hermenéutico a la Arqueología, sugerimos imprescindible diferenciar dos tipos de significados del objeto arqueológico: en primer término, el significado funcional sujeto a las cualidades intrínsecas como material. En dicho sentido, el significado del objeto se desarrolla a partir de su relación con otros factores y procesos, en relación con las estructuras sociales y económicas. Y en segundo lugar, el significado que contiene los símbolos e ideas. Para poder acceder a este tipo de significado debemos de tener en cuenta que, como intérpretes accedemos al pasado con todos nuestros paquetes de prejuicios (Carbonelli, 2011: 5)

Discusiones y desafíos en torno a la relación entre Arqueología y Hermenéutica en general y más precisamente en la llamada "Arqueología Hermenéutica", puede verse reflejada en Vaquer (2013)

El libro Social Theory and Archaeology de Shanks y Tilley (1987) representa un intento de incorporar los postulados posmodernos a la práctica arqueológica, y realizar una crítica de la Arqueología Procesual (AP). Uno de los puntos centrales del libro es que la AP produce una escisión entre el pasado y el presente, al postular la existencia de un sentido objetivo en el pasado que debe ser reconstruido por 
los arqueólogos. En lugar de esto último, los autores proponen que el pasado solamente existe en relación con el presente, en la práctica presente de la interpretación. Por lo tanto, la arqueología es un discurso, un sistema de expresión estructurado de reglas, convenciones y significados para la producción de significados y conocimientos. Conocer el pasado implica producirlo en el presente (Vaquer, 2013: 161)

La crítica del autor, alcanza también a los trabajos de Hodder:

Otra consecuencia de la analogía textual es que la metodología arqueológica tiene como objetivo interpretar los significados de la cultura material. En Theory and Practice in Archaeology, Hodder (1995), propone que es posible ir más allá de los usos físicos inmediatos de los objetos hacia los significados simbólicos más abstractos (Vaquer, 2013: 161)

Con respecto al vínculo entre perspectivas metodológicas de las Ciencias Sociales y su impacto en Arqueología, en el caso de la Fenomenología: "Con respecto a la filosofía, una de las corrientes que más se usó (y se abusó) fue la fenomenología, especialmente durante la década de 1990 y hacer una nueva reaparición en la corriente autodenominada "arqueología simétrica" o posteriormente "nuevo materialismo" (Olsen 2007). La fenomenología fue utilizada por la arqueología hermenéutica como vía para superar dos problemas de la arqueología procesual. El primero de ello es la ausencia del sujeto en las interpretaciones del pasado, producto del determinismo ecológico y la falta de poder causal de la agencia humana" (...)

El segundo problema para el que se usó la fenomenología fue la superación de dicotomías propias del pensamiento moderno, en particular la división entre cuerpo y mente cuyo fundamento se encuentra en la filosofía cartesiana y persiste en el pensamiento científico positivista (Vaquer, 2018: 623-624)

En el caso de la Teoría Fundamentada, Sironi (2014) plantea una ampliación epistemológica y metodológica de la Arqueología de la minería, utilizando por un lado a Hodder y por otro la Teoría Fundamentada:

Esta relación entre discursividad y sociedad podemos visualizarla en la disciplina arqueológica, a través de los componentes que forman un sitio arqueológico, ya que dichos componentes son considerados como un texto simbólico enmarcado en un contexto, y dicho texto debe ser leído en el sentido de interpretarlo. Por lo tanto, la cultura material es un texto en el que "pudieron existir una multiplicidad de lecturas en el pasado". (...) "la utilización de la triangulación, la aplicación de la teoría fundamentada; y el rescate de historias de vida de mineros actuales para la aplicación de la inferencia analógica (Sironi, 2014: 162).

Gonzáles Espino (2014) propone utilizar la Teoría Fundamentada, en el marco de un diseño de investigación cualitativa, para ordenar conocimientos a través de constructo, dimensiones e indicadores aplicados al estudio de los estilos de cerámica.

En cuanto al uso de la Teoría de la Acción Participativa en Arqueología, Almansa Sánchez (2017) la aplica a la Arqueología Pública. Para Rincón Díaz (2017) a investigación acción participativa a partir de los postulados de Orlando Fals Borda, es una alternativa para abordar el colonialismo intelectual y científico en Latinoamérica, (ideas que son compartidas por la Arqueología Histórica).

Silva; Zabala y Fabra (2019) reflexionan sobre el uso de la Cartografía Social como propuesta 
teórica metodológica para el estudio, valoración y gestión del patrimonio arqueológico. Álvarez Larrain y McCall (2019) proponen la cartografía participativa como andamiaje teórico-metodológica aplicada a un estudio de arqueología del paisaje latinoamericano. En relación a la aplicación de las narrativas al ámbito arqueológico (Gluzman, 2013), tanto como el trabajo de Quesada, Gastaldi y Moreno (2015), entre tantos otros.

\section{La Arqueología Histórica y el anclaje metodológico}

¿Hasta qué punto se puede introducir un análisis en Arqueología Histórica que se conciba a nivel teórico como: Hermenéutica Simbólica, Analógica u Objetiva?; y en segundo lugar: ¿qué uso de tradiciones metodológicas se ha hecho dentro del área? Por un lado (Andrén, 1998) y (Arriola Silva. 2015), mencionan la utilización del documento para obtener información pertinente, tanto como notas de campo (aportes que provienen de la Historia tanto como de la Arqueología)

En algunas oportunidades el arqueólogo se convierte en historiador, al reunir información pertinente en los hallazgos culturales, su investigación histórica y su aportación para la reconstrucción histórica. En este planteamiento, la Historia y la Arqueología coinciden en la fuente común de investigación: el documento. La Arqueología presenta los vestigios culturales como documentos, entre ellos: los murales, la cerámica, las estelas, la escritura jeroglífica, la arquitectura, los códices; la Historia también encuentra en los documentos de archivo, fotografías, periódicos, crónicas, mapas y planos, referencias para su investigación” (Arriola Silva, 2015: 565).

Lucas (2006. 2010) alude a la combinación de restos materiales e inmateriales, tanto como narrativas más amplias en el ámbito de la Arqueología Histórica. Y Wilkie (2006) sostiene el uso del registro escrito y su reflexión como una interacción entre investigador y objeto. Para Olsen (2003), los documentos históricos son similares a los artefactos, ya que ambos explican por sí mismos la variabilidad cultural.

Landa y Ciarlo (2016) definen el ámbito de la Arqueología Histórica como:

La Arqueología Histórica puede definirse tentativamente como la especialidad dedicada a la investigación del pasado reciente del ser humano, que en el caso de América cubre el rango temporal que se inicia con la invasión de los europeos al continente, por intermedio de la evidencia material producto de sus actividades y de otras fuentes de información tales como documentos escritos, pinturas, fotografías y registros orales" (Landa y Ciarlo, 2016: 96)

Por otro lado, el carácter interdisciplinario de la Arqueología Histórica, se caracteriza por compartir teoría y metodologías con otras disciplinas, entre ellas la Historia, Antropología, Sociología, Filosofía, Geografía, Biología, Economía, Ecología, Arquitectura, entre otras.

La Hermenéutica Simbólica puede cumplir un rol preponderante a la hora de desentrañar aspectos de la propia práctica científica como "la actitud simbólica del investigador: circunscribir la realidad como símbolo"; el análisis de los símbolos discurso e iconográfico de individuos, grupos o culturas como material empírico; "la comprensión del símbolo como medio de investigar un tema/problema de estudio"; "la lectura del símbolo mediante los procedimientos "dejar que suceda", "concebir y objetivar y "confrontarse con y diferenciarse de".

La Hermenéutica Analítica proporcionaría instancias de validación de la interpretación del lengua- 
je con el que se describen tanto objetos como procesos, en cualquier instancia de la investigación, ya que permanentemente debemos describir y argumentar en torno a objetos o textos, particularmente se utilizará para aclarar el sentido literal (manifiesto) como analógico (latente) de las expresiones. Ya que es característica de la Hermenéutica Analítica lograr interpretaciones claras y distintas, tanto como rigurosas.

En cuanto a la Hermenéutica Objetiva, provee un andamiaje dónde es posible el trabajo de caso, el análisis en secuencia de todo el proceso investigativo (tanto histórico cuanto arqueológico), tanto como el uso de documentos y objetos, y se ajusta particularmente a la práctica en contexto.

En relación con las tradiciones metodológicas mencionadas en el apartado anterior, nuevamente el alcance interdisciplinario de la Arqueología Histórica permite su uso, ya que la Hermenéutica está intrínsecamente ligada al Análisis de Contenido, tanto desde un punto de vista sincrónico como diacrónico.

Los aportes de la Fenomenología, intervienen en las disquisiciones de razonamiento de los investigadores en el proceso completo de investigación.

La Teoría Fundamentada puede ser aplicada en torno a aspectos vinculados a muestreo tanto como al análisis de contenido.

La Teoría de la Acción Participativa, provee andamiaje para trabajar aspectos "internos" (conformación de grupos de investigación, y sus relaciones con el entorno), tanto como "externos" (muy estudiados en el ámbito de la Arqueología Histórica y que hacen a las relaciones de poder, entorno político, entre otros (referidos a la reconstrucción de casos en contexto).

La Cartografía Social, predominantemente se puede enfocar sobre aspectos territoriales y de circulación de la información. En tanto que las Narrativas están presentes en todo proceso investigativo, sobre todo en la observación directa.

\section{Conclusión}

En las distintas variantes de Hermenéutica abordadas en este texto, existe un origen común de desarrollo histórico desde la antigüedad hasta la historia contemporánea, pero claramente hay diferenciación disciplinar en las nombradas, ya sea desde el ámbito de la Psicología a la Antropología; o desde la Filosofía del Lenguaje a la Antropología y Etnografía; y desde la Sociología hacia otros campos disciplinares en el marco de las Ciencias Sociales.

En segundo lugar; se han descripto tradiciones metodológicas en Ciencias Sociales, tales como: Hermenéutica, Teoría Fundamentada, Fenomenología, Teoría de la Acción Participativa, Cartografía Social y las Investigaciones Narrativas. Cada una de ellas proveen andamiajes investigativos vinculados con un enfoque cualitativo, y con el desarrollo de estrategias de recolección y análisis de datos. Y se muestran ejemplos de utilización en Arqueología.

En tercer lugar, se introdujo la diferenciación de niveles de problemas en los que se ha estudiado el vínculo entre Arqueología e interpretación: Nivel $\mathrm{N}^{\circ} 1$ : Teórico/epistemológico; nivel N² : Problemas de interpretación a partir de diferenciación de enfoques descriptivos; nivel $\mathrm{N}^{\circ} 3$ : Problemas de interpretación disciplinar común; nivel Nㅜㄴ Problemas de Interpretación en Arqueología Histórica a nivel metodológico; y nivel $\mathrm{N}^{\circ}$ 5: Problemas de Interpretación en práctica situada específica, y esto debido al uso indistinto del término "interpretación" en trabajos arqueológicos.

Finalmente, frente a las preguntas: ¿Hasta qué punto se puede introducir un análisis en Arqueología Histórica que se conciba a nivel teórico como: Hermenéutica Simbólica, Analógica u Objetiva?; y en segundo lugar: ¿qué uso de tradiciones metodológicas se ha hecho dentro del área?, situándonos en el anclaje metodológico, la respuesta es que es posible aplicar tanto a nivel teórico como metodológico 
los tipos de Hermenéutica mencionados, tanto como los diferentes enfoques metodológicos (en cuanto a definición de método, estrategias de recolección y análisis de datos).

\section{Referencias bibliográficas}

ALMANSA SÁNCHEZ, J. (2017) Arqueología y sociedad: interacción y acción desde la teoría crítica. Universidad Complutense de Madrid. Madrid. Documento descargado de: https://eprints.ucm. es/48147/1/T40055.pdf

ÁlVAREZ BALANDRA, A. C.; BEUCHOT, M. Y ÁlVAREZ TENORIO, V. (2018) Reflexiones y aplicaciones de la Hermenéutica Analógica en la educación. Universidad Pedagógica Nacional. México

ÁLVAREZ LARRAIN, A. Y M. K. MCCALL (2019) La cartografía participativa como propuesta teórico-metodológica para una arqueología del paisaje latinoamericana. Un ejemplo desde los Valles Calchaquíes (Argentina). Antípoda. Revista de Antropología y Arqueología 36: 85-112. https://doi.org/10.7440/antipoda36.2019.05

ÁLVAREZ VIDAURRE, E. (2007) Interpretación en Arqueología. Teorías del conocimiento. Cuadernos de Arqueología. Universidad de Navarra 15, 2007, Pp. 9-30. Documento descargado de: https:// revistas.unav.edu/index.php/cuadernos-de-arqueologia/article/view/27731/23361

ANDRÉN, A. (1998) Between Artifacts and Texts Historical Archaeology in Global Perspective. (Pp. 105-144) Plenun Press. N.Y. Documento descargado en: https://www.springer.com/gp/ $\underline{\text { book} / 9780306455568}$

ARRIOLA SILVA, A. L. (2015) Arqueología Histórica: otra manera de hacer Arqueología. En: XXVIII Simposio de Investigaciones Arqueológicas en Guatemala (editado por B. Arroyo, L. Méndez Salinas y L. Paiz. Pp. 563-572. Museo Nacional de Arqueología y Etnología, Guatemala. Documento descargado: http://www.asociaciontikal.com/wpcontent/uploads/2017/07/Simp28-46-Arriola.pdf

ARRÁEZ, M.; CALLES, J.Y MORENO DE TOVAR, L. (2006) La Hermenéutica: una actividad interpretativa Sapiens. Revista Universitaria de Investigación, vol. 7, núm. 2, diciembre, 2006, pp. 171-181. Universidad Pedagógica Experimental Libertador. Caracas, Venezuela. Documento descargado de: https://www.redalyc.org/pdf/410/41070212.pdf

BEUCHOT, M. (2000) Tratado de Hermenéutica Analógica. Hacia un nuevo modelo de interpretación. Universidad Autónoma de México.

BEUCHOT; M. (2011) Historia de la Filosofía del Lenguaje. Fondo de Cultura Económica. México.

BEUCHOT, M. (2015) Elementos esenciales de una hermenéutica analógica. Revista Diánoia. Vol. LX, $\mathrm{N}^{\circ}$ 4, mayo. (Pp. 127-145). Documento descargado de: www.scielo.org.mx-pdf-dianoia

BEUCHOT, M. (2006) Puentes hermenéuticos hacia las humanidades y la cultura. Universidad Iberoamericana. México.

CÁRCAMO, H. (2005). Hermenéutica y Análisis Cualitativo. Cinta de Moebio. Revista de Epistemología 
de Ciencias Sociales, (23). Documento descargado de: https://cintademoebio.uchile.cl/index.php/ CDM/article/view/26081/27386

CARBONELLI, J. P. (2011) La interpretación en Arqueología, pasos hacia la Hermenéutica del Registro. Prometaica. Revista de Filosofía y Ciencias. Año 2. Número 5. Pp. 5-17. Buenos Aires. Documento descargado de: Dialnet-LaInterpretacionEnArqueologiaPasosHaciaLaHermeneut-4806161.pdf

CONDE GAXIOLA, N. (2004) Breve historia del movimiento de la Hermenéutica Analógica (19932003). Dianoia, Vol. XLIX, N52, mayo 2004. Pp.147-162. Documento descardado de:

dianoia.filosoficas.unam. $m x>$ article $>$ download

D'AMORE, L. (2015) En las superficies del presente. Disquisiciones sobre el método de excavación arqueológica. Relaciones de la Sociedad Argentina de Antropología XL (2), julio-diciembre 2015. Pp. 501-522. Documento descargado de: Dialnet-EnLasSuperficiesDelPresenteDisquisicionesSob reElme-6381101.pdf

FLICK, U. (2009) Introducción a la investigación cualitativa. Ed. Morata. Madrid.

GLUZMAN, G. (2013) Narrativas arqueológicas de momentos de contacto en los Valles Calchaquíes hasta mediados del siglo XX; Arqueología. Vol. 19. N*1. Universidad Nacional de Buenos Aires. Pp. 1-16. Documento descargado de: http://revistascientificas.filo.uba.ar/index.php/Arqueologia/ article/view/1683

GONZÁLEZ ESPINO, D. (2014) Estilo en Arqueología. Pp. 1-15. Documento descargado de: https://www. academia.edu/37541670/ESTILO_EN_ARQUEOLOG\%C3\%8DA_ESTUDIO_CUALITATIVO

GONZÁlEZ RUIBAL, A. (2012) Hacia otra Arqueología: Diez propuestas. Complutum, 2012, Vol. 23 (2) Pp. 103-116. Universidad Complutense. Madrid. Documento descargado de: https://www. academia.edu/2349457/Hacia_otra_arqueolog\%C $3 \% \mathrm{ADa}$ diez propuestas

GÜRTLER, L.; HUBER, L. (2007) Métodos de pensar y estrategias de la investigación cualitativa. Liberabit. Lima Perú. (13: 37-52)

HODDER, I. (1986) Reading the Past: Current Approaches to Interpretation in Archaeology. Cambridge University Press. Uk.

HODDER, I. (1995) Theory and Practice in Archaeology. Routledge. London.

JUNG, C. (1984) El hombre y sus símbolos. Caralt Editor. Barcelona.

LANDA, C. Y CIARLO, N. (2016) “Arqueología Histórica: Especificidades del campo y problemáticas de estudio en Argentina. QueHaceres. Revista del Departamento de Ciencias Antropológicas. Universidad Nacional de Buenos Aires. N³/96. Pp. 96-120. Buenos Aires. Documento descargado: revistas.filo.uba.ar/index.php/quehaceres/article/download/2997/943

LÓPEZ AUSTIN, L. (1995) Tras un método de estudio comparativo entre las cosmovisiones Mesoamericana y Andina a partir de sus mitologías. Antrop., 32 (1995), Pp. 209-240. Documento descargado de: https://www.semanticscholar.org/paper/Tras-un-m\%C3\%A9todo-de-estudiocomparativo-entre-las-y-a-Austin/922c101f35e0f78d1 ebac5c28c4ff63fob635727 
LUCAS, G. (2006) Historical Archaeology and time. En: Hicks, D.; Beaudry, M. Eds. The Cambridge Companion to Historical Archaeology. Cambridge University Press. UK. Pp. 34-47. Documento descargado de: https://www.cambridge.org/core/books/cambridge-companion-to-historicalarchaeology/historical-archaeology-and-time/540D95D8CC59AAF1F4DBDE32D6764BBF

LUCAS, G. (2010) Time and the archaeological archive. Rethinking History. The Journal of Theory and Practice. Vol. 14/3 (Pp. 343-359). Documento descargado de: https://doi.org/10.1080/13642529.2 $\underline{010.482789}$

MANTZAVINOS, C., (2016) "Hermeneutics", The Stanford Encyclopedia of Philosophy (Spring 2020 Edition), Edward N. Zalta (ed.), URL Documento descargado de: https://plato.stanford.edu/ archives/spr2020/entries/hermeneutics/

MANCHADO VILLORIA, M. (2017) Aplicación del método hermenéutico. Una mirada al horizonte. (Pp.1- 6) Documento descargado de: https://redsocial.rededuca.net/aplicacion-del-metodohermeneutico

MARTÍN SILVA, V.; ZABALA, M. Y FABRA, M. (2019) Cartografía Social como recurso metodológico para el análisis patrimonial. Experiencias de mapeo en Miramar (Córdoba, Argentina). Retratos del Territorio: Perspectivas contemporáneas en historia de la cartografía y cartografía histórica. Universidad Pedagógica y Tecnológica de Colombia. Vol 24, N*2. Pp. 1-17. Documento descargado de: https://revistas.uptc.edu.co/index.php/perspectiva/article/view/8631

OLSEN, B.; JOHANSEN, H. (1992) Hermeneutics and Archaeology: On the Philosophy of Contextual Archaeology. American Antiquity. Vol. 57. N* 3 (July 1992). Pp. 419-436. Cambridge University Press.

OLSEN, B. (2003) "Material Culture after Text: Re-Membering Things". Norwegian Archaeological Review, 36, n. 2, pp. 87-104.

OLSEN, B. (2007) “Keeping things at arm's length. A genealogy of asymmetry”. World archaeology 39 (4), pp. 579-588.

ORTÍZ OSES, A. (1983) Jung y la Antropología. Pp. 182-193. Temas de Antropología Aragonesa. Instituto Aragonés de Antropología. España. Documento descargado de: https://antropologiaaragonesa.org/ pdf/temas/1.13 Jung_y_la.pdf

ORTÍZ OSES, A. (1986) Antropología Hermenéutica. Anthropos. Vol. 56. Barcelona.

ORTÍZ OSES, A. Y LANCEROS, P. (Eds.) (2006). La interpretación del mundo. Cuestiones para el tercer milenio. Anthropos. UNAM. México.

PÉREZ, D.A. (2011) La Hermenéutica y los métodos de investigación en Ciencias Sociales. Estudios Filosóficos. n44 diciembre de 2011 Universidad de Antioquia pp. 9-37. Documento descargado de: http://www.scielo.org.co/pdf/ef/n44/n44a02.pdf

QUESADA, M.; GASTALDI M. Y MORENO, E. (2015) Narrativas arqueológicas públicas e identidades indígenas en Catamarca. Revista Arqueología Pública 2(1) 57. Universidad Estadual de Campinas. Documento descargado de: https://www.researchgate.net/publication/322777950 Narrativas 
arqueologicas publicas_e identidades indigenas_en_Catamarca

RAMOS, M. (1999) Algo más que la Arqueología de sitios históricos. Una opinión. Anuario de la Universidad Internacional SEK. N5, 1999, pp.61-75. Documento descargado de: http://www. proarhep.com.ar/wp-content/uploads/Anuario-SEK-19991.pdf

REICHERTZ, J. (2004) Objective Hermeneutics and Hermeneutic Sociology of Knowledge. A Companion to Qualitative Research. Edited by Uwe Flick, Ernst von Kardorff and Ines Steinke. Sage Publications. London (pp. 290-295).

RINCÓN DÍAZ; J. (2017) La investigación acción participativa en Orlando Fals Borda y la Subversión del Orden Social. Universidad Santo Tomás. Bogotá.Documento descargado de: https://repository. usta.edu.co/bitstream/handle/11634/9270/AbdulJonathan2017.pdf?sequence=1\&isAllowed=y

RIVAS, Y. Y BRISEÑO, J. (2012) La Hermenéutica: sus orígenes, evolución y lo que representa en este convulsionado período. Revista Academia - Trujillo - Venezuela - Julio-Septiembre. Volumen XI (23) 2012. Documento descargado de: http://www.saber.ula.ve/bitstream/handle/123456789/37627/ articulo3.pdf:jsessionid=E8E7C842E6987320041E1165FCF5397E? sequence $=1$

SHANKS,M.;TILLEY,C.(1987)SocialTheoryandArchaeology.University of New Mexico.Albuquerque. Documento descargado de: http://ndl.ethernet.edu.et/bitstream/123456789/51727/1/24. Michael\%20Shanks\%20and\%20Christopher.pdf

SIRONI, O. (2014) Arqueología Histórica Industrial: Propuesta epistemológica y metodológica para una Arqueología de la minería. Entelequia Revista Interdisciplinar. Universidad de Málaga. N* 17. Pp. 155-168 Documento descargado de: https://ri.conicet.gov.ar/bitstream/ handle/11336/30497/CONICET_Digital_Nro.bcf6133d-e2f4-44a2-a4e2-c415ad12d87b_A. pdf? sequence $=2$ \&isAllowed $=\mathrm{y}$

SOLARES ALTAMIRANO, B. (2012) Mircea Eliade, Imaginario religioso y Hermenéutica. Acta Sociológica, num 57, enero-abril 2012. Pp.33-49. UNAM. México. Documento descargado de: http://www.revistas.unam.mx/index.php/ras

STAKE, R. (1999) Investigación con estudios de casos. Ediciones Morata. Madrid.

TEIXEIRA VILELA, R. Y NOACK-NAPOLES, J. (2010) Hermeneutica objetiva e sua apropiacao na pesquisa empírica na ádea da educacao. Linhas Críticas, vol. 16, núm. 31, julio-diciembre, 2010, pp. 305-326 Universidade de Brasilia Brasilia, Brasil. Documento descargado de: https://www. redalyc.org/pdf/1935/Resumenes/Resumen_193517492007_1.pdf

VAQUER, J. M. (2018) Una descripción fenomenológica del "objeto arqueológico". Volumen 50, $\mathrm{N}^{\circ}$ 4, 2018. Páginas 623-632 Chungara Revista de Antropología Chilena. Documento descargado de: https://scielo.conicyt.cl/pdf/chungara/v50n4/0717-7356-chungara-01802.pdf

VAQUER, J. M. (2015) Arqueología, Hermenéutica y la pregunta sobre el pasado. Apuntes para una mirada interdisciplinaria. Corpus. Archivos Virtuales de la Alteridad Americana. VOL 5, NO 2 | 2015 Julio / Diciembre 2015 Documento descargado de: https://journals.openedition.org/ corpusarchivos $/ 1505$ 
VAQUER, J. M. (2013) Las aporías de la Arqueología Hermenéutica. En busca de un nuevo criterio de validez. Arqueología 19. Pp.151-172. Instituto de Arqueología. Facultad de Filosofía y Letras. Universidad Nacional de Buenos Aires. Buenos Aires. Documento descargado de: $1679-$ Texto\%20 del\%20manuscrito-3414-1-10-20151016.pdf

VECHIS, L.G. (2018) A Hermeneutica junguiana em estudo: Aplicacoes possiveis na pesquisa qualitativa em psicología. Revista de Psicologia, Fortaleza, v.9 n2, Pp. 21-30. Documento descargado de: http://www.periodicos.ufc.br/psicologiaufc/article/view/18806

VERGARA SILVA, F., YÁÑEZ MACÍAS V. Y ROGER BARTRA, B. (2016). De la Antropología Cultural a la Antropología del cerebro. Cuicuilco, vol. 23, núm. 65, enero-abril, 2016, Pp. 233-248. Escuela Nacional de Antropología e Historia. México. Documento descargado de: https://www. redalyc.org/pdf/351/35145329012.pdf

WILKIE, L. (2006) Documentary Archaeology. En: Hicks, D.; Beaudry, M. Eds. The Cambridge Companion to Historical Archaeology. Cambridge University Press. UK. (13-33). Documento descargado de: https://doi.org/10.1017/CCO9781139167321.002

ZABALA, X. (2007) ¿Un psicoanálisis hermenéutico? Revista de Psicología, vol. XVI, núm. 1, 2007, Pp. 9-40. Universidad de Chile. Santiago, Chile. Documento descargado de: https://revistapsicologia.uchile.cl/index.php/RDP/article/view/18469

Recibido: 10-04-2020

Aceptado: $27-07-2020$ 